Mohammed T. Hayajneh*, Mohammed A. Almomani, and Mu'ayyad M. Al-Shrida

\title{
Effects of Waste Eggshells addition on Microstructures, Mechanical and Tribological Properties of Green Metal Matrix Composite
}

https://doi.org/10.1515/secm-2019-0027

Received October 25, 2018; accepted May 21, 2019

\begin{abstract}
Chicken eggshell (Es) waste is an industrial byproduct, and its disposal constitutes a severe environmental risk. Eggshell is a new engineering reinforcement retaining excellent properties such as low density, renewable, eco-friendly, and high thermal stability. The current research aims to study the effects of eggshell particles addition on microstructures, mechanical and tribological properties of aluminium/eggshell green metal matrix composites (MMCs). In the present work Al-Es metal matrix composite is produced by powder metallurgy processes. SEM with EDX and XRD were used to examine the microstructures and the compounds that arise during the sintering process of the produced composites. Six tests were conducted on the produced samples including; dry wear test, micro Vickers hardness, and ultimate compressive strength. The results showed that the addition of $3 \mathrm{wt}$. \% of eggshell improved wear resistance (65\%), compressive strength (40\%) and hardness (15\%). At 6 and 9 wt. \% of eggshell, negative results appeared.
\end{abstract}

Keywords: Aluminum matrix composite; eggshell; green composites; powder metallurgy; wear

\section{Introduction}

Metal matrix composites (MMCs) are engineering materials that rapidly replace monolithic materials due to

\footnotetext{
${ }^{\star}$ Corresponding Author: Mohammed T. Hayajneh: Industrial Engineering Department, Faculty of Engineering, Jordan University of Science and Technology, P.O. Box 3030, Irbid, 22110, Jordan, Email: hayajneh@just.edu.jo

Mohammed A. Almomani: Industrial Engineering Department, Faculty of Engineering, Jordan University of Science and Technology, P.O. Box 3030, Irbid, 22110, Jordan, E-mail: maalmomani7@just.edu.jo

Mu'ayyad M. Al-Shrida: Industrial Engineering Department, Faculty of Engineering, Jordan University of Science and Technology, P.O. Box 3030, Irbid, 22110, Jordan, E-mail: mmalshrida15@eng.just.edu.jo
}

their excellent properties such as specific strength, fatigue strength, wear resistance, thermal and electrical conductivity and creep resistance. These properties make MMCs suitable for many applications that range from marine to aerospace industries $[1,2]$. Common metals that have been used as a matrix include aluminum, titanium and magnesium [3]. Among them, aluminum matrix is the most common one due to its light weight, high stiffness and corrosion resistance [4-6].

Usually, metal matrix is combined with ceramic particles to incorporate metal matrix properties with ceramic properties. Metals are characterized by toughness and ductility. Meanwhile, ceramics are characterized by high strength. This combination leads to higher strength and lower wear rate $[7,8]$. Ceramic materials can be found in different forms such as long fibers, short fibers (whisker), particles and filaments. Particulate composites have an advantage over other forms of composites because they have isotropic properties $[9,10]$. Ceramic particles that were used as a reinforcement to fabricate MMCs include alumina $\left(\mathrm{Al}_{2} \mathrm{O}_{3}\right)$, silicon carbide ( $\left.\mathrm{SiC}\right)$, boron carbide $\left(\mathrm{B}_{4} \mathrm{C}\right)$, graphite $(\mathrm{Gr})$, carbon nanotubes $(\mathrm{CNTs})$, carbon $(\mathrm{C})$, silicon oxide $\left(\mathrm{SiO}_{2}\right)$, fly ash (FA), eggshells (Es) and others [11-15].

MMCs can be fabricated by several methods such as powder metallurgy (PM), compo-casting, gas pressure infiltration, squeeze casting, stir casting, spray deposition and injection molding [2, 16-21]. Powder metallurgy method is the most common process that is used to fabricate MMCs with discontinuous reinforcements because it possesses some advantages over other methods; including: lower cost because PM method is performed at lower temperature, lower chemical reactions between the phases and high distribution of reinforcement in the matrix [22].

Environment-friendly, "green" composite materials based on natural waste are increasingly being developed for various applications as replacements for synthetic materials $[23,24]$.

Among ceramic particles, eggshells retain many properties, e.g. low density, costless, renewable, ecofriendly and thermal stability at high temperature [25-29]. These 
properties make eggshells as a candidate to reinforce aluminum and its alloys which usually suffer from wear and hardness problems [30].

A literature review on aluminum matrix was conducted, and the results showed that different ceramic reinforcements significantly affect microstructure, magnetic, physical, thermal, electrical and mechanical properties such as tensile and compression strength, wear, stiffness, hardness and others. For example, Moutsatsou et al. [31] prepared aluminum composite by reinforcing it with 5 , 10 and 15 wt. \% of fly ash (FA). After that, they discovered that FA can increase the hardness even with clustering. Zircon $\left(\mathrm{ZrSiO}_{4}\right)$ is another type of ceramic particles that was incorporated with aluminum by Mazahery and Shabani [30] who studied the tribological behavior of aluminum/ $\mathrm{ZrSiO}_{4}$ composite under different loads and sliding distances.

In another investigation, El-kady and Fathy [32] examined the effect of silicon carbide particles size and its amount on physical and mechanical properties of $\mathrm{SiC} /$ aluminum composite. Liu et al. [33] studied the effect of reduced graphene oxide ( $\mathrm{rGO}$ ) and graphene nanosheets (GNSs) on microstructure and mechanical properties of aluminum matrix. They found that $\mathrm{rGO}$ and GNSs were uniformly dispersed in aluminum matrix. Moreover, these reinforcements increased aluminum composite hardness. Developing aluminum composite is continuous, where Tan et al. [34] emphasized that hybrid reinforcement (titanium diboride \& silicon carbide) gave better results when compared to mono silicon carbide.

Moreover, several studies have been done about the effect of eggshells particles on aluminum matrix. Hassan and Aigbodion [1] investigated the effect of adding eggshell on $\mathrm{Al}-\mathrm{Cu}-\mathrm{Mg}$ alloy. The results showed improvement on hardness, density and tensile strength. Dwivedi et al. [35] examined density, tensile strength, hardness and fatigue strength of aluminum alloy AA2014 reinforced by 5 wt. \% eggshell. The results showed that hardness, tensile strength and fatigue strength were increased by 33\%, 32.9\%, 19.55\%, respectively. Recently, Sharma and Dwivedi [36] have been reinforced aluminum alloy AA2014 matrix by hybrid reinforcement based eggshell. Specific strength, physical behavior, and thermal expansion of the composite were investigated.

According to the literature, numerous points can be concluded. First, ceramic particles can generally improve aluminum matrix properties. Second, eggshells can increase hardness. Finally, nobody studied the effect of eggshells on tribological properties. So that, the current research suggests a new reinforcement, eggshells, that may lead to solve the aforementioned aluminum matrix problems.

\section{Experimental Details}

\subsection{Materials characterization}

Since the powder characteristics, such as its size, shape, density and distribution, play a vital role on the mechanical properties of the produced composites, it is very necessary to present the primary state of used powders before compaction process [37]. In the current work, commercially pure aluminum of $99 \%$ purity was used as matrix material having a particle size of 200 mesh $(74 \mu \mathrm{m})$. Al powder was received from Acros Organics (USA). The shape of the matrix was investigated by scanning electron microscope (Quanta ${ }^{\mathrm{TM}} 450 \mathrm{FEG}$ SEM). It is clear from Figure 1 that no significant morphological changes can be seen between the matrix particles. The SEM image of the matrix shows an elongated sub-angular particle shape. Also, it is seemed from the figure that there is no significant difference in the size between the particles. Moreover, the density of $\mathrm{Al}$ is $2.7 \mathrm{~g} / \mathrm{cm}^{3}$ as taken from the supplier company (Acros Organics).

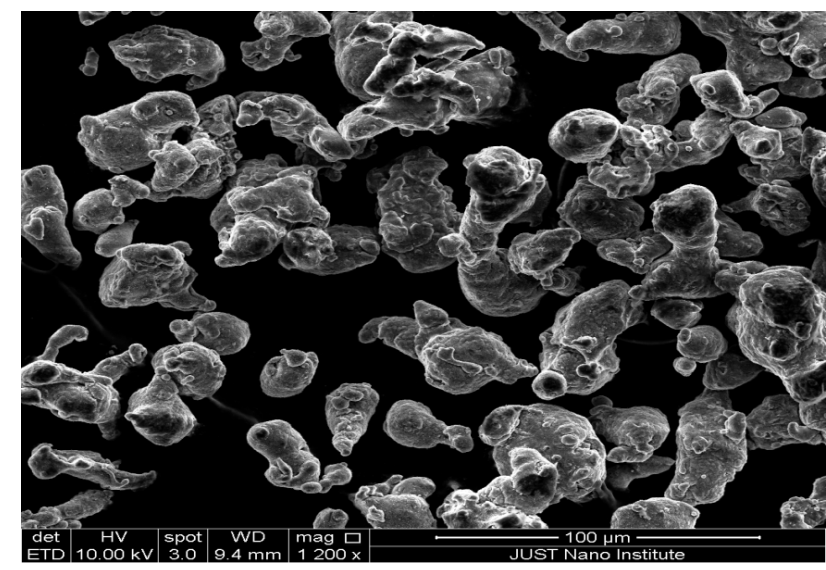

Figure 1: SEM micrograph of elongated sub-angular Al matrix.

In this work, eggshells (Es) powder was used as a reinforcement material. Preparation of Es reinforcement passes through many steps. First, raw eggshells were collected from the nearby bakery. Second, eggshells were cleaned by rain water and dried in the sun to remove impurities and unpleasant odors. Third, the flaking process was obtained. In other words, large shells were converted to flakes by a plastic hammer. Fourth, Es flakes were con- 


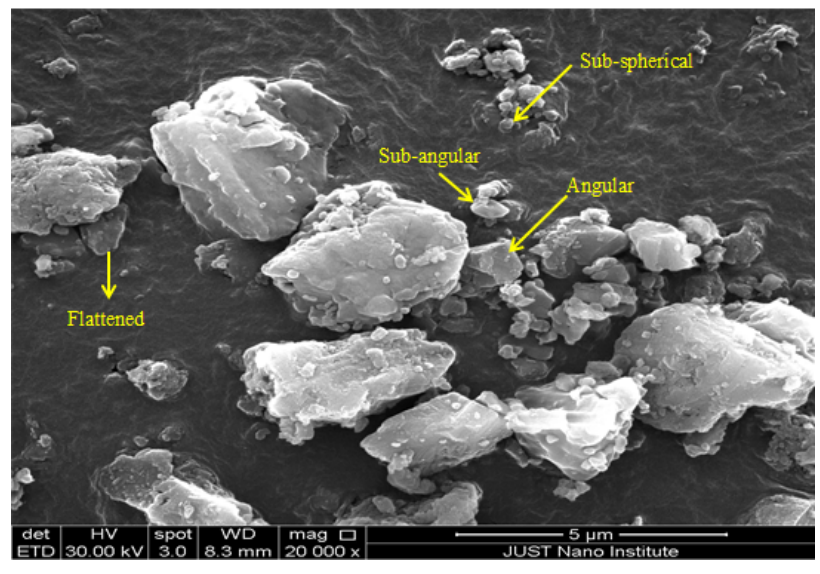

Figure 2: SEM micrograph of irregular shapes and sizes of carbonized Es.

verted to powder by a blender. Fifth, carbonization process was obtained at $500{ }^{\circ} \mathrm{C}$ for $3 \mathrm{~h}$ to eliminate carbonaceous materials, e.g. membrane. The presence of carbonaceous materials causes porosity, where during the sintering process they vaporized and burned off leaving pores. Finally, pulverized Es was sieved by Retsch sieve shaker. The obtained size from sieve shaker is less than $50 \mu \mathrm{m}$. However, SEM micrograph in Figure 2 shows irregular shapes and sizes of carbonized Es. The shapes of these particles are angular, sub-angular, sub-spherical and flat. Further, it is obvious from the scale in the SEM image that there is a wide range of particles size ranging from nano scale to micro scale. The irregularity of size and shape may be attributed to the used manner of converting the Es flakes to powder (i.e. shear action which results from the blade of blender). The insulator material, e.g. ceramic materials, cannot be shown by SEM because discharging will occur. For this reason, the eggshells powder as a ceramic material was coated by an $8 \mathrm{~nm}$ thin layer of gold using spatter coater (model Q 150R ES). In any case, the experimental density of carbonized Es was calculated by Archimedes rule using the average of three trails to get more accurate results. The results showed that Es density is $2.5 \mathrm{~g} / \mathrm{cm}^{3}$. In order to investigate the chemical elemental composition of carbonized Es particles, Energy-dispersive X-ray spectroscopy (EDX) was used. Furthermore, the investigation of the compounds of carbonized Es powder was conducted by Ultima IV X-ray diffractometer.

Aluminum particles always are covered by oxides (alumina, $\mathrm{Al}_{2} \mathrm{O}_{3}$ ) which form a passive layer that goes between metallic aluminum particles. This layer cannot be removed or broken by aluminum sintering heat preventing solid state sintering, i.e. Preventing metal-metal contacts between two adjacent particles during sintering. In this regard, the amorphous oxide layer can be removed by incorporating a small amount of magnesium $(\mathrm{Mg})$ as a sintering aid. Magnesium reacts with alumina in deoxidization reaction to form crystalline spinel $\left(3 \mathrm{MgAl}_{2} \mathrm{O}_{4}\right)$ and/or (3MgO). Crystalline particles instead of amorphous particles can be bonded [38, 39]. Moreover, Tin (Sn) was used to fill the voids between aluminum particles because it melts during the sintering process, thereby increasing the sample density [40].

\subsection{Design and manufacturing of compaction mold}

To carry out the fabrication process, a mold was designed and manufactured in the local workshop at Jordan University of Science and Technology (JUST). Figure 3 presents the manufactured mold under UTM.

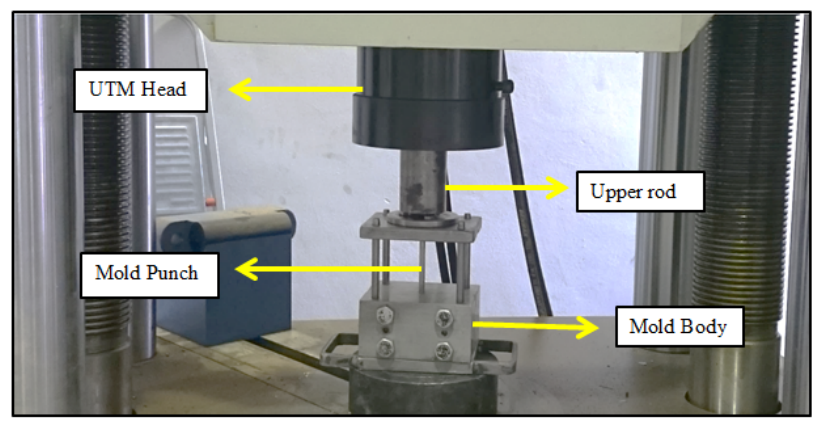

Figure 3: Compaction process using UTM.

\subsection{Compressibility curve}

Excessive pressure needs increasing in input power, and it leads to an adverse effect on the die. Therefore, the solution comes from what is called the compressibility curve (densification curve). It is a curve that is used to determine the suitable pressure to press the powder mixture. This curve represents the relationship between the relative density of green compact and the applied pressure [41, 42]. Relative density is defined as the ratio of experimental to theoretical density [43]. The best pressure can be taken from the curve when the curve looks like straight (or when there is no significant difference in the experimental density between two produced compact). 


\subsection{Fabrication of composites}

Next to preparation of eggshells, 4 specimens of aluminum composite were prepared using different percentages of eggshells. In order to improve sintering response, sintering additives, tin $(\mathrm{Sn})$ and magnesium $(\mathrm{Mg})$, were added. 1.5 wt. \% of $\mathrm{Mg}$ was added for each sample to reduce the amount of alumina. Furthermore, 1.5 wt. \% of Sn was added to perform liquid phase sintering in order to reduce the porosity of the samples. $1.5 \mathrm{Mg}$ and $1.5 \mathrm{Sn}$ were added as Macaskill et al. [39] suggested. The percentages of used powders are shown in Table 1.

After pouring the powders into the mold cavity, a single action press was applied at $475 \mathrm{MPa}$ as concluded from compressibility curve in Figure 5. The compaction process was carried out by installing a universal testing machine punch UTM (model WAW-2000H) on the upper rod that is connected with HSS punch by mold plate as shown in Figure 3.

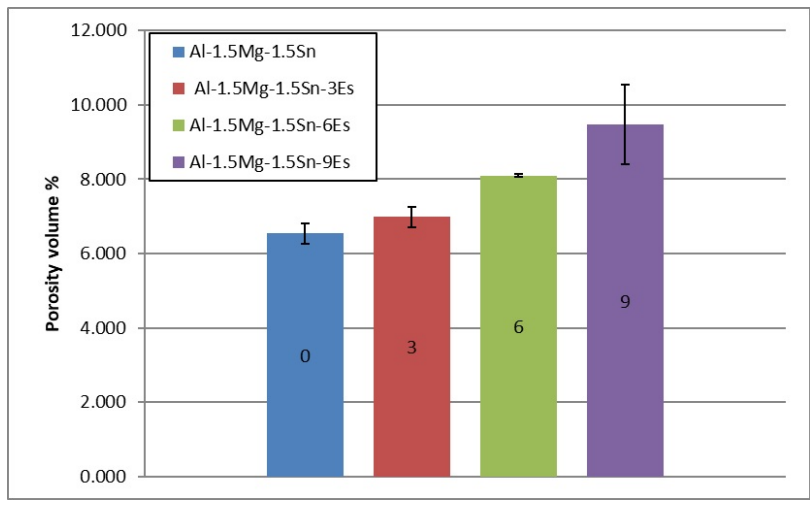

Figure 4: Porosity volume percentage of all fabricated composites.

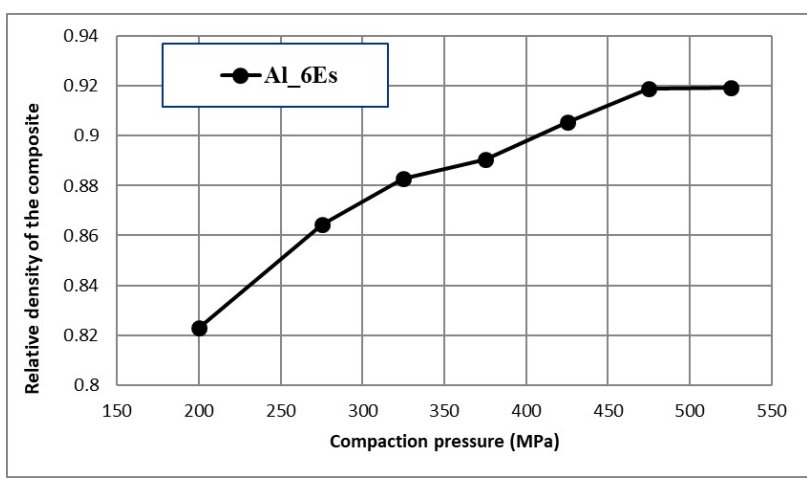

Figure 5: Densification curve of Al-6 wt. \% Es composite.

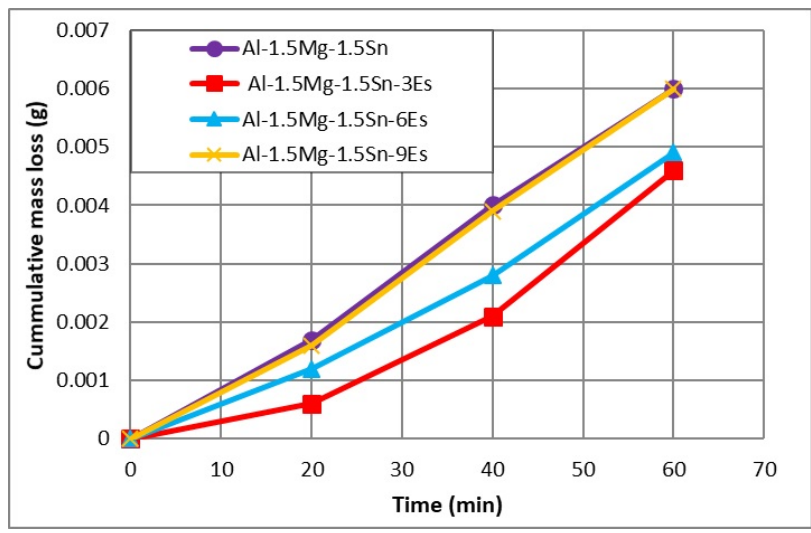

Figure 6: Variation of cumulative mass loss of Al-1.5Mg-1.5Sn-Es composites with varying eggshells percentage and sliding time.

To reduce the friction between the powder mixture and the cavity wall during compaction and to facilitate sample ejection, a thin layer of zinc stearate lubricant, purchased from Sigma-Aldrich (USA), was used. In the next stage, the produced samples from the compaction process are fragile, and they are not completely processed. So, they were sintered at $630{ }^{\circ} \mathrm{C}$ as Macaskill et al. [39] suggested. Sintering was carried out without atmospheric protective in an electrical furnace, Nabertherm muffle furnace. To reduce the amount of oxygen that reacts with samples during sintering, the sample was placed in a bed of sand. Sintering additives such as $\mathrm{Sn}$ and $\mathrm{Mg}$ were added to improve sintering response as mentioned before.

\subsection{Measuring density and porosity of the manufactured composites}

There are two methods to measure the density; the first one by using Archimedes rule (buoyancy rule) and the second one by using geometrical method [44]. In the current work, theoretical density of the composite was determined by rule of mixture, and it can be mathematically expressed as in equation 1 [33]. In contrast, experimental density was determined from the geometrical method [45]. However, porosity can be determined as a function of theoretical and experimental density. Equation 2 shows how porosity volume percentage is calculated [46].

$$
\rho_{\text {Composite }}=\frac{100}{\frac{w_{1}}{\rho_{1}}+\frac{w_{2}}{\rho_{2}}}
$$

$\rho_{1}$ - density of the first material powder $\rho_{2}$ - density of the second material powder $w_{1}$ - weight percentage of the first material powder 
Table 1: Sample designation and reinforcement weight percentages.

\begin{tabular}{lllll}
\hline $\begin{array}{l}\text { Sample } \\
\text { No. }\end{array}$ & Sample designation & $\begin{array}{l}\text { Es } \\
\text { (wt. \%) }\end{array}$ & $\begin{array}{l}\text { Mg } \\
\text { (wt. \%) }\end{array}$ & $\begin{array}{l}\text { Sn } \\
\text { (wt. \%) }\end{array}$ \\
\hline $\mathbf{1}$ & Al-1.5Mg-1.5Sn & 0 & 1.5 & 1.5 \\
$\mathbf{2}$ & Al-1.5Mg-1.5Sn-3Es & 3 & 1.5 & 1.5 \\
$\mathbf{3}$ & Al-1.5Mg-1.5Sn-6Es & 6 & 1.5 & 1.5 \\
$\mathbf{4}$ & Al-1.5Mg-1.5Sn-9Es & 9 & 1.5 & 1.5 \\
\hline
\end{tabular}

$w_{2}$ - weight percentage of the second material powder

Volumeporosity $(\%)=$

$=(1-($ sintereddensity/theoreticaldensity $)) \times 100 \%$

\subsection{Wear test}

The wear test was carried out by a pin on disk apparatus (model TM 200, Gunt, Hamburg). A pin on disk apparatus uses rotating hardened steel disk against the cylindrical sample, i.e. composites pin. The pin is pressed over the disk by a dead weight loading device. The wear loss was reported according to ASTM G99-95a [47]. The test was replicated 3 times in a cumulative manner to study the effect of time (a function of sliding distance) on mass loss, where the interval time for each replicate was $20 \mathrm{~min}$ (corresponding to $314.16 \mathrm{~m}$ ) and $60 \mathrm{~min}$ as a total time (942.5 m). Long interval time, i.e. $20 \mathrm{~min}$, was used to produce a measurable mass loss. The parameters used in the current study were set at applied force of $25 \mathrm{~N}$ and rotational speed of $100 \mathrm{rpm}$ (corresponding to $0.2618 \mathrm{~m} / \mathrm{s}$ ). However, the material of the counter disk is made of hardened stainless steel with hardness of $645 \mathrm{HV}$ and surface roughness of $0.22 \mu \mathrm{m}$.

The morphology of cylindrical compact that produced from the sintering process was not clear enough during micro Vickers hardness test. Therefore, different steps were carried out to clarify the diamond pyramid on the surface. The first step was rough polishing using sand papers of 320 and 800 grits. Next step was fine polishing by $0.3 \mu \mathrm{m}$ diamond paste (alumine suspension, PRESI). After that, the sample surface was cleaned by acetone, and finally, the samples were taken to a micro hardness test machine (Model MHT_1, Tokyo, Japan). The parameters of the hardness machine were set at $100 \mathrm{gf}$ load and at $10 \mathrm{~s}$ dwell time. Seven readings were taken from different locations of the sample surface.

\subsection{Compression strength test}

The compressive strengths of all samples were evaluated from the true stress-strain curve which obtained from a computerized universal testing machine (Quasar 100) with maximum capacity $100 \mathrm{KN}$. The cross head speed was set at $2 \mathrm{~mm} / \mathrm{min}$ for all tests. In any case, the samples were in the shape of a cylinder with $8.3 \mathrm{~mm}$ in diameter and 15.3 - $15.7 \mathrm{~mm}$ in height (aspect ratio 1.9 - 1.96). To reduce the barreling shape effect, a thin layer of grease was placed on the machine bench and cross head.

\subsection{X-Ray Diffraction (XRD)}

To investigate the compounds (if existed) that arise during the sintering process, XRD test was conducted by Ultima IV X-ray diffractometer using $\mathrm{CuK} \alpha$ with $2 \theta$ ranging from $20^{\circ}-80^{\circ}$ at $40 \mathrm{kV}$ voltage, $40 \mathrm{~mA}$ current intensity and $4^{\circ} / \mathrm{min}$ speed. For more convenience, the sample containing 6 wt. \% of Es was analyzed. In addition, the base sample also was analyzed to make a comparison between the base sample, Al-1.5Mg-1.5Sn, and the samples that containing Es particles.

\subsection{Microstructure and Surface Morphology}

The morphology properties such as distribution of reinforcements, clustering, porosity, cracks, fractures and particles - matrix interfaces were investigated using a scanning electron microscope (SEM). The samples for microstructure were prepared by abrasive sheets of 320 and 800 grits and finally polished by $0.3 \mu \mathrm{m}$ diamond paste.

\section{Results and Discussion}

\subsection{Density and porosity}

Table 2 shows theoretical and experimental density and porosity. For easier interpretation, the porosity in Table 2 is 
represented by Figure 4. As shown in Figure 4, increasing Es percentages caused the porosity to increase. It is clear from the figure that adding 9 wt. \% of Es leads to the high amount of porosity when compared to the reference sample (Al-1.5Mg -1.5Sn). Meanwhile, the addition of 3 wt. \% of Es causes a slight difference in porosity volume percentage.

\subsection{Compressibility curve}

Figure 5 shows relative density Al- 6 wt. \% Es composite as a function of compaction pressure. In general, the relative density of the produced sample increases with increasing the compaction pressure. The suitable pressure can be taken from the curve in Figure 5. According to Figure 5 , it was noted that the suitable pressure was $475 \mathrm{MPa}$, where all pressures after $475 \mathrm{MPa}$ did not produce any difference of relative density. Hence, maximum density was achieved at $475 \mathrm{MPa}$, where the relative density was $92 \%$. However, increasing the pressure above $475 \mathrm{MPa}$ will cause more power consumption without any enhancement in the density. Moreover, the compressibility curve indicates that the densification rate is higher at low pressure which may attribute to the voids that not yet filled by particles. It is noticeable that the densification rate from 200 to $275 \mathrm{MPa}$ is higher than that from 425 to $475 \mathrm{MPa}$.

\subsection{The effect of eggshells percentage and sliding time on wear loss}

The plot of mass loss for the effect of the eggshells reinforcement is displayed in Figure 6. It is clear that the addition of $3 \mathrm{wt}$. \% of Es has a significant role in reducing the mass loss especially during the first 20 min (first period). Adding 3 Es wt. \% to Al-1.5Mg-1.5Sn matrix decreases the mass loss from $0.0017 \mathrm{~g}$ to $0.0006 \mathrm{~g}$, i.e. that the enhancement of wear resistance is approximately $65 \%$. This refers to the presence of hard Es particles, had a good bonding with Al-1.5Mg-1.5Sn matrix, that act as a load carrier and a barrier against plastic deformation. Further, the Es protrusions prevent the disk asperities from reaching to Al1.5Mg-1.5Sn matrix. Similar results were proved by the presence of $\mathrm{SiC}$ and fly ash $[14,19,48]$. At 6 wt. \% Es, it is observed that wear resistance reduced from $65 \%$ to $29 \%$, but the wear loss is still better than the base matrix. It is attributed to the formation of Es clusters which are motivated by increasing Es percentages. This behavior, i.e. the tendency of Es to form clusters was proved in SEM micrographs later. Increasing wear rate affected by the agglom- eration phenomenon of reinforcement particles also was reported by other researchers [49-51]. At 9 wt. \% Es, no significant difference in the mass loss is observed. The addition of 9 wt. \% Es decreases the wear resistance more and more, where the wear resistance improvement reaches only $5 \%$. The continuous reduction in the wear resistance here can also be related to the increasing in the number of clusters which accompanied with porosity.

Moreover, the effect of sliding time (as a function of sliding distance) on Al-1.5Mg-1.5Sn-(X) Es composites is also shown in Figure 6. It is clear that with increasing the time the mass loss increased. This is obvious from the slope of curves. With increasing the time, the slope of the curves becomes more inclined (steeper). In other words, the slope during the first period (after $20 \mathrm{~min}$ ) was less steep than the slope during the second (after $40 \mathrm{~min}$ ) and the third period (after $60 \mathrm{~min}$ ) which indicates lower mass loss during the first period. This may refer to the pulling out phenomenon that increases with sliding time due to wearing of the Al-1.5Mg-1.5Sn matrix which held the Es particles. A similar trend was reported by the presence of $\mathrm{SiC}$ instead of Es by other researchers [48, 52]).

\subsection{The effect of eggshells percentage on micro hardness}

Figure 7 shows an effect of eggshells addition to Al-1.5Mg1.5Sn matrix on the hardness property of the powdered composites. The hardness value of Al-1.5Mg-1.5Sn matrix (eggshells free) is $30.3 \mathrm{HV}$. Addition of 3 wt. \% of Es increases the hardness from 30.3 to $35 \mathrm{HV}$. This means that the hardness is improved by about $16 \%$. Beyond $3 \mathrm{wt} . \%$ of Es (i.e., at 6 and 9), the hardness values decreased again, but it is still higher than that obtained by the base matrix. However, the improvement at 6 wt. \% of Es and 9 wt. \% of Es is $7 \%$ and 5\%, respectively. The descending trend of hardness values after addition 3 wt. \% of Es may be attributed to the clusters that accompanied by porosity as discussed in microstructure and surface morphology and in wear results. A similar effect of Es particles on $\mathrm{Al}$ matrix was obtained by Hassan and Aigbodion [1], Chaithanyasai et al. [12] and Dwivedi et al. [35].

\subsection{The effect of eggshell percentage on compressive strength}

Figure 8 illustrates the effect of different levels of Es wt. \% on the compressive strength of the aluminum matrix, Al1.5Mg-1.5Sn. The participating Es particles results in higher 
Table 2: Theoretical, experimental, and relative density and porosity volume percentage of all produced samples.

\begin{tabular}{llllll}
\hline $\begin{array}{l}\text { Sample } \\
\text { No. }\end{array}$ & Composite type & $\begin{array}{l}\text { Sintered density } \\
\left(\mathbf{g} / \mathbf{c m}^{3}\right)\end{array}$ & $\begin{array}{l}\text { Theoretical } \\
\text { density } \\
\left(\mathbf{g} / \mathbf{c m}^{3}\right)\end{array}$ & Relative density & $\begin{array}{l}\text { Porosity volume } \\
(\%)\end{array}$ \\
\hline $\mathbf{1}$ & Al-1.5Mg-1.5Sn & $2.526 \pm 0.0076$ & 2.703 & $0.935 \pm 0.0030$ & 6.539 \\
$\mathbf{2}$ & Al-1.5Mg-1.5Sn-3Es & $2.508 \pm 0.0073$ & 2.697 & $0.930 \pm 0.0027$ & 6.986 \\
$\mathbf{3}$ & Al-1.5Mg-1.5Sn-6Es & $2.473 \pm 0.0016$ & 2.690 & $0.919 \pm 0.0006$ & 8.092 \\
$\mathbf{4}$ & Al-1.5Mg-1.5Sn-9Es & $2.430 \pm 0.0286$ & 2.684 & $0.905 \pm 0.0105$ & 9.471 \\
\hline
\end{tabular}

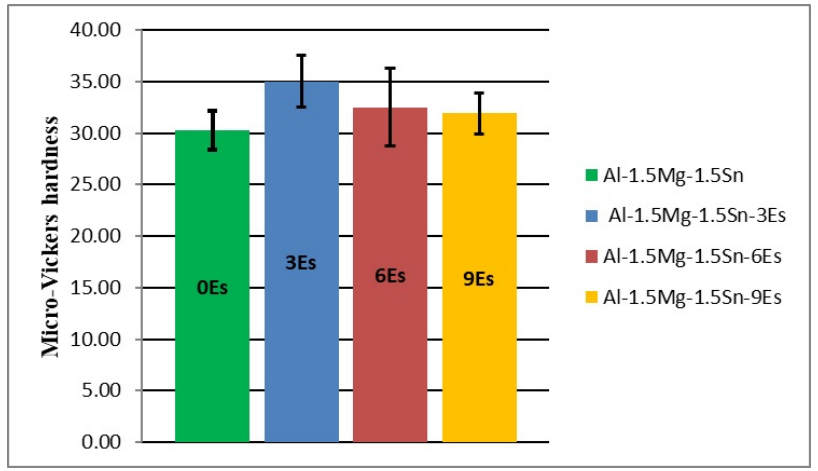

Figure 7: The hardness values against eggshells content in Al1.5Mg-1.5Sn-(X)Es composites.

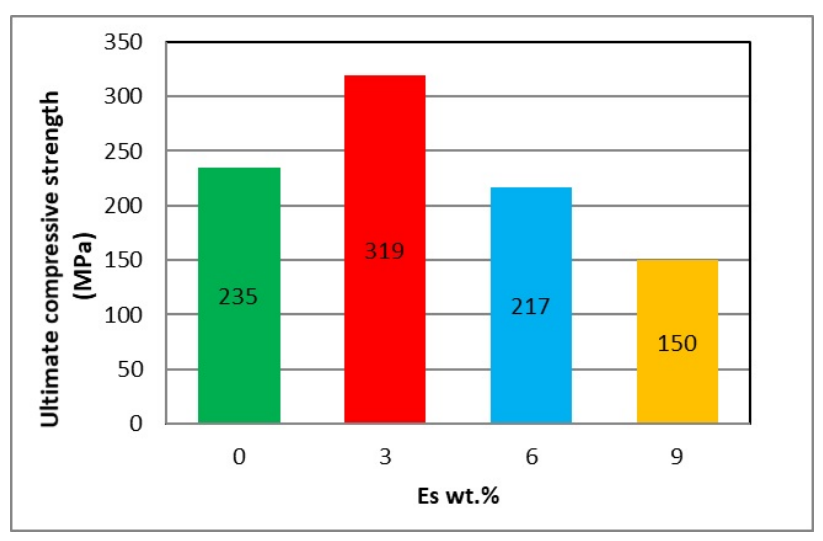

Figure 8: Bar graph of compressive strength of Al-1.5Mg-1.5Sn-(X)Es composite.

compressive strength of $\mathrm{Al}-1.5 \mathrm{Mg}-1.5 \mathrm{Sn}$ matrix. The presence of Es particles, as a ceramic material, between Al1.5Mg-1.5Sn matrix particles impedes the dislocation movements which mean higher resistance to plastic deformation and hence higher compressive strength. Increasing of Es wt. \% from (0) to (3) results in improvement of compressive strength by about $40 \%$. At (6) and (9) Es wt. \%, the descending trend of compressive strength appeared. In fact, with increasing of Es beyond 3 wt. \%, the distribution of Es particles change and they tend to agglomerate in some regions. These agglomerations are accompanied with poros-

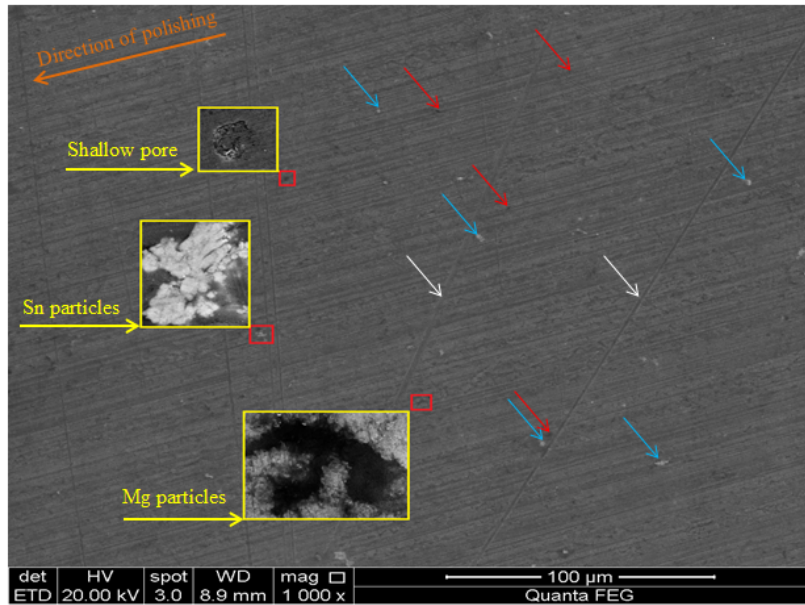

Figure 9: SEM micrographs of polished surface of Al-1.5Mg-1.5Sn matrix showing the lowest amount of porosity. Blue arrows indicate to $\mathrm{Sn}$ particles, red arrows indicate to $\mathrm{Mg}$ particles and white arrows indicate to scratches. Yellow squares represent higher magnification for red squares.

ity as shown by SEM images in section 3.6. This porosity reduces bonding and compressive strength. A similar effect was noted by Abdizadeh et al. [51] for $\mathrm{MgO}$ reinforced aluminum matrix composite.

\subsection{Microstructure and surface morphology}

SEM image of the sintered microstructure of Al-1.5Mg-1.5Sn is shown in Figure 9. It can be seen from the figure that the wetting agent magnesium (red arrows, dark phase) and filler $\mathrm{Sn}$ (blue arrows, bright phase) exhibit a homogenous distribution in aluminum matrix, but a molten tin cannot be wetted at the oxidized surface of the sample. This result is in agreement with what is reported by Macaskill et al. [39]. Moreover, it is clear from the figure that the tin particles were melted during the sintering process because the shape of tin particles after the sintering process is different from the shape before sintering. Furthermore, the figure shows the direction of polishing and scratches (white arrows) that found on the sample surface. Porosity which 
is encountered in PM is responsible for reducing the mechanical properties [54]. In any case, Figure 9 (at 0 wt. \% of Es) presents a lower amount of porosity when compared to Figure 10(b-c) (at 6 and 9 wt. \% of Es, respectively).

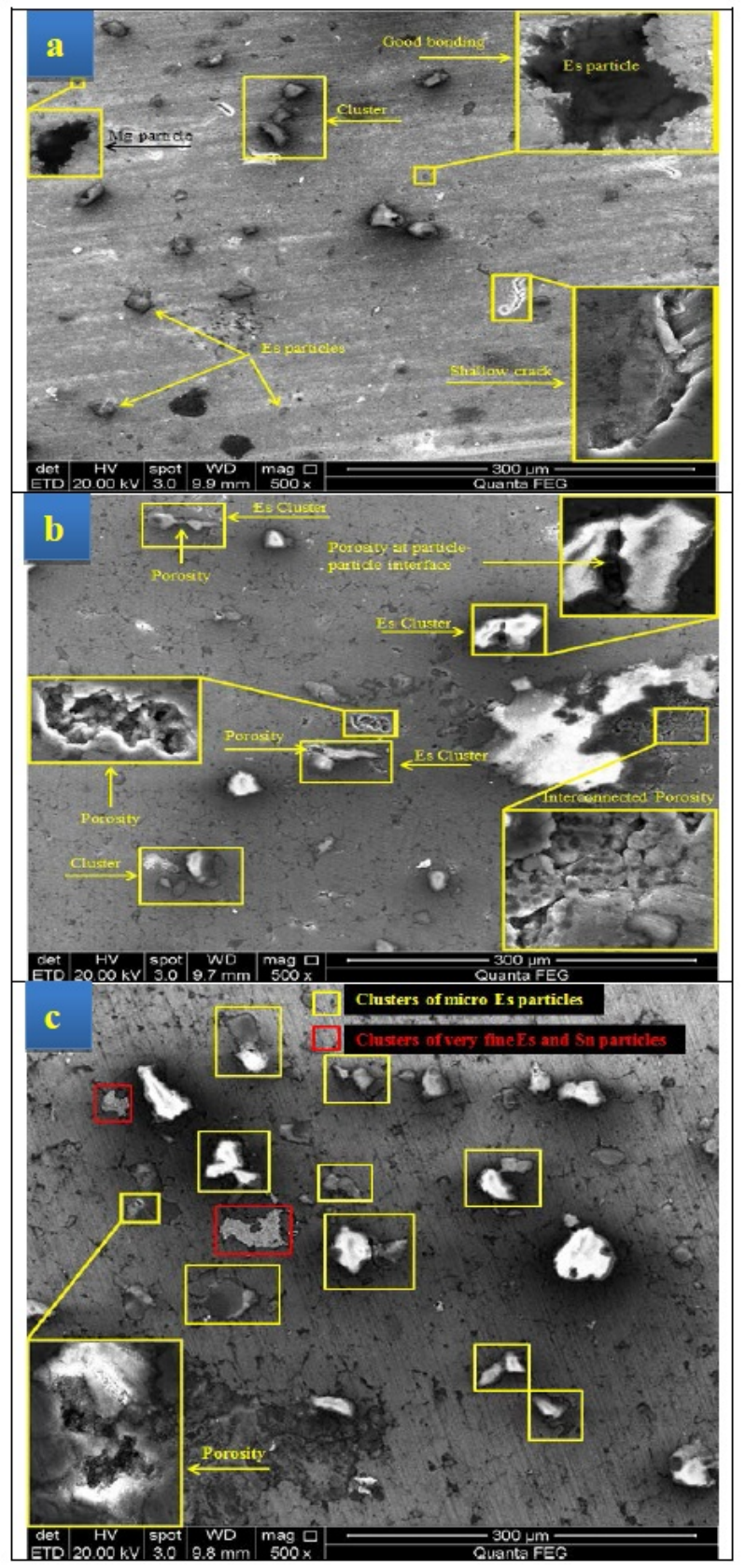

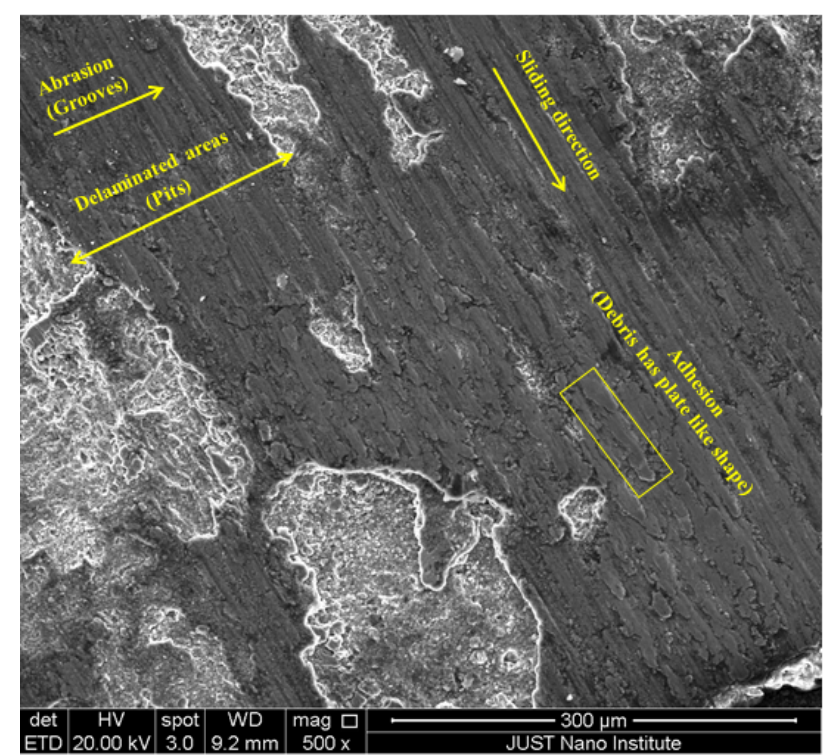

(a)

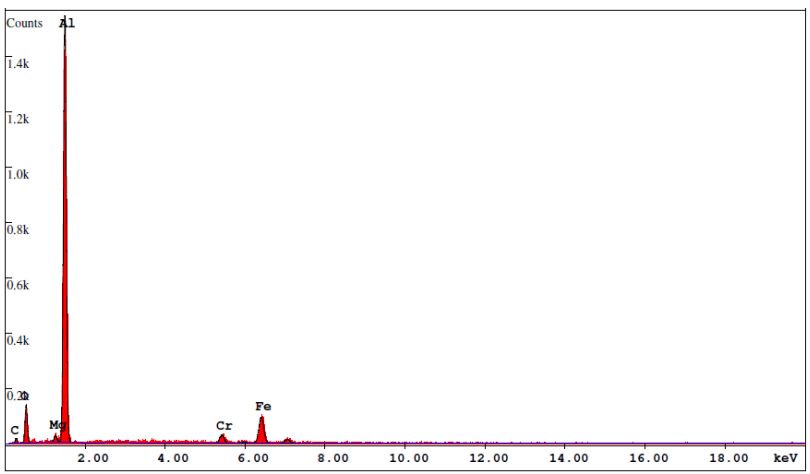

(b)

Figure 11: (a) SEM micrograph of worn out surfaces of Al-1.5Mg$1.5 \mathrm{Sn}$ composite showing three types of wear; abrasion, adhesion, and delamination wear, (b) EDX analysis of worn surface of Al-1.5Mg-1.5Sn composite.

With respect to the composites that containing Es particles, a detailed review of microstructural characterization is presented in the current section. Investigation on microstructures of Al-1.5Mg-1.5Sn-3Es composite fabricated by PM technique revealed a uniform distribution of Es particles throughout Al matrix with a low number of clusters. In addition, good bonding between Es particles and $\mathrm{Al}$ matrix is confirmed. Furthermore, the presence of deep porosity and cracks is approximately absent. These details are visible in Figure 10(a). From Figure 10(b), it is obvious that micrograph of Al-1.5Mg-1.5Sn composite containing 6 Es wt. \% (i.e., Al-1.5Mg-1.5Sn-6Es) exhibited a higher number of clusters and porosity which may be responsible for increasing mass loss, decreasing hardness and decreasing compressive strength. Further, the clusters num-
Figure 10: (a) SEM image of Al-1.5Mg-1.5Sn-3Es composite showing uniform distribution of particles and good bonding at matrixparticle interface, (b) SEM image of Al-1.5Mg-1.5Sn-6Es composite showing higher number of clusters accompanied with porosity at particle-particle interface and (c) SEM micrograph of Al-1.5Mg1.5Sn-9Es composite showing the highest number of clusters which accompanied with porosity at particle-particle interface. 


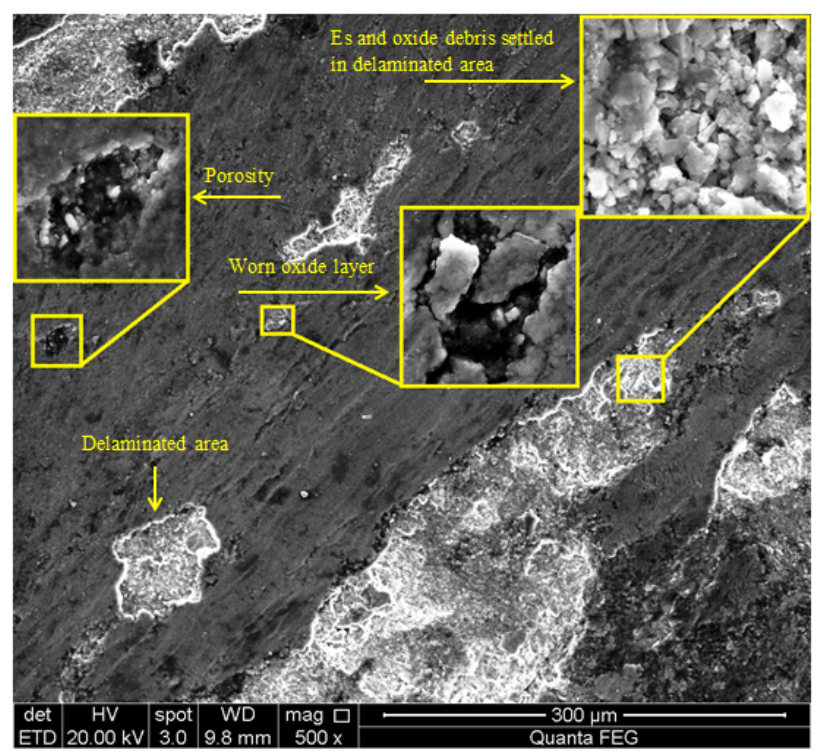

(a)

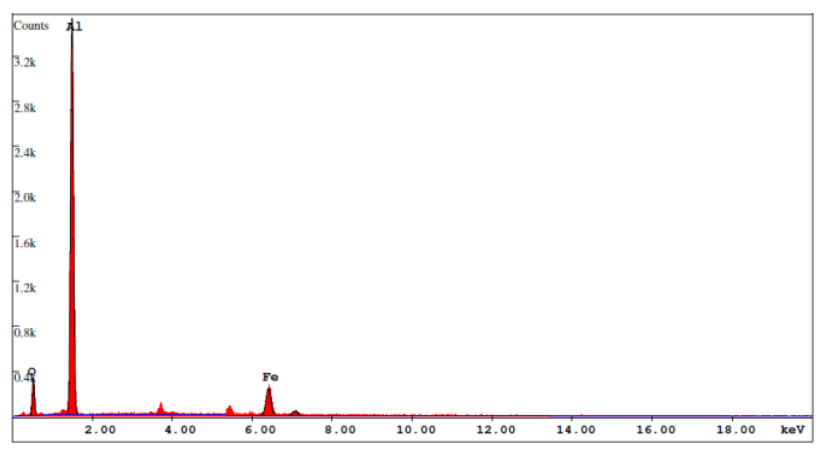

(b)

Figure 12: (a) SEM micrograph of worn out surfaces of Al-1.5Mg1.5Sn-3Es composite showing smooth hard oxide layer and delaminated area, (b) EDX of marked worn oxide layer of Al-1.5Mg-1.5Sn3 Es presented in (a).

ber and porosity level in the composite containing 9 wt. $\%$ Es were more than those of the composite containing 3 and 6 wt. \% Es. Similar results obtained by Thandalam et al. [55]) for another reinforcement type.

\subsection{Worn surface morphology}

Analyzing the surfaces of composite materials after the wear test is essential to understand the wear mechanism that occurs in these composites. The SEM micrographs and EDX patterns in Figures 12-15 show the worn out surfaces and wear mechanism of developed aluminum composites using different percentages of Es.

The sample that containing 0 wt. \% of Es (base sample) exhibits four types of wear, including; abrasive, adhe-

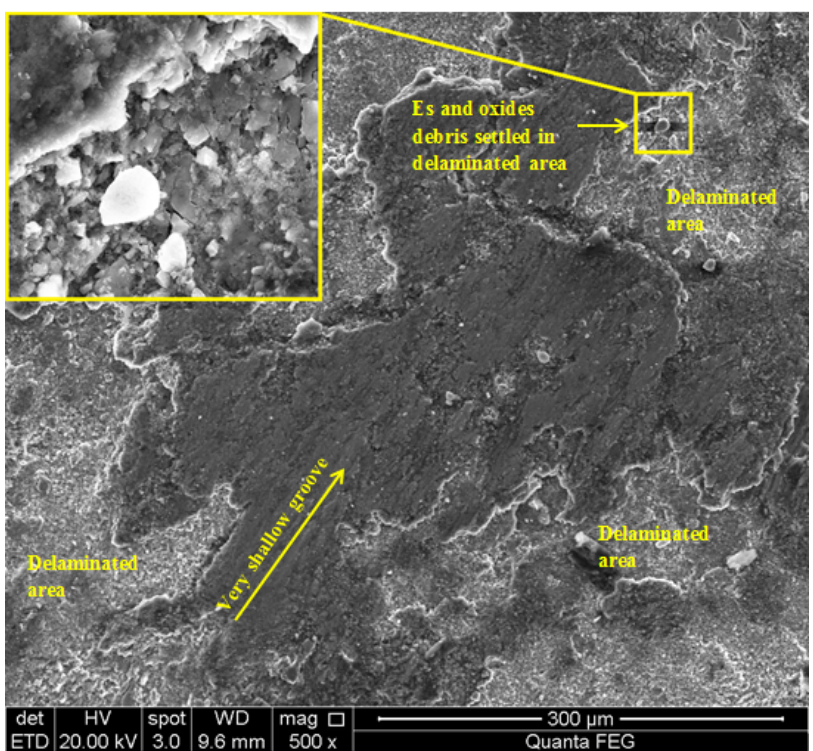

(a)

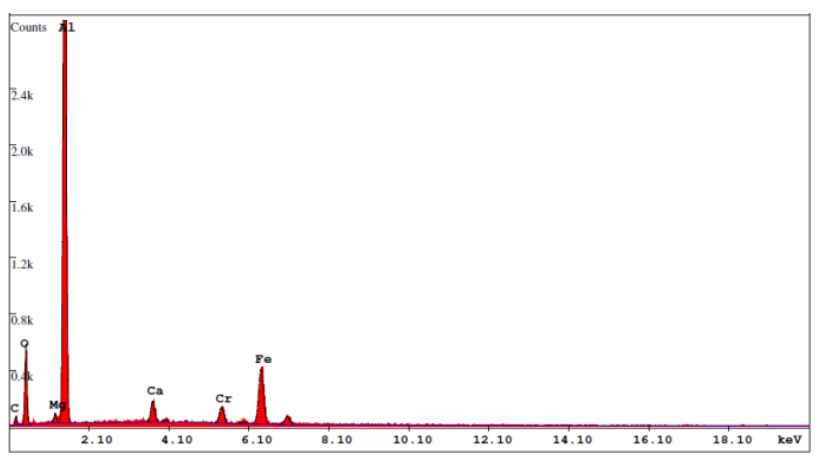

(b)

Figure 13: (a) SEM micrograph of worn out surfaces of Al-1.5Mg1.5Sn-6Es composite showing large delaminated areas and Es and oxide debris discovered by EDX, (b) EDX analysis of worn surface of Al-1.5Mg-1.5Sn-6Es.

sive, delaminated and oxidative wear. Figure 11(a) presents the first three types. Meanwhile, Figure 11(b) presents the fourth type that is oxidative wear. Many continuous grooves which are parallel to the direction of sliding are clear in Figure 11(a). Grooves are the evidence on the abrasive wear. The width and depth of grooves indicates the amount of material removal from the sample surface. Generally, wider and deeper grooves occurred in the unreinforced metals when compared to those that reinforced by particles. The second type is an adhesive wear which is demonstrated by the existence of debris which has a platelike shape. The presence of pits in SEM micrograph is evidence on the third type that is delaminated wear. All of these symptoms are shown in Figure 11(a). However, presence of oxygen peak in EDX pattern, Figure 11(b), confirms the fourth type that is oxidative wear. This type of 
wear arises from continuous friction between two surfaces leading to frictional heat generation, thereby oxidation on the surface. Furthermore, the EDX pattern shows iron and chromium peaks which mean that wear occurs in the counter face disk, where the asperities from the counter face steel disk is transferred to the sample surface. Our result is consistent with what is presented by Hassan et al. [19], Sahin et al. [56] and Wei et al. [57].

SEM micrographs of worn surfaces and debris highlight the type of wear mechanisms which occurred in the composites that containing Es particles. Regarding to the Al-1.5Mg-1.5Sn-3Es composite in Figure 12(a), it can be seen that the abrasive and adhesive wear approximately are absent. This behavior may be attributed to protrusions of the Es particles that prevent the steel disc asperities from reaching to the Al matrix, i.e. preventing metal to metal contact, thus decreasing mass loss. Further, the figure shows oxide debris, discovered by EDX, which is settled in delaminated areas. In addition to that, gradual forming of an oxide layer is motivated due to temperature increasing with increasing sliding distance. Oxidative layer acts as a solid lubricant which means it can prevent metal to metal contact. The EDX pattern of the marked worn oxide layer in Figure 12(a) is presented in Figure 12(b). When the steel disk asperities reach the oxide layer, small debris from the oxide layer is removed. This means that the fresh $\mathrm{Al} \mathrm{ma-}$ trix is exposed to oxygen, thereby fresh matrix quickly reacts with oxygen to form a new oxide layer. Removing and forming oxide layer is cyclic. Since the oxide layer is hard, its debris is fine (Figure 12(a)), thereby lower mass loss in oxidative regions.

The same behavior is observed in the worn surface of composite that containing 6 wt. \% of Es except that the delaminated areas are becoming larger as shown in Figure 13(a). It may refer to Es clusters that accompanied with porosity. Because most of these clusters are surrounded by porosity, they may easier to remove from the matrix when cyclic external force is applied causing larger delaminated areas, thus material removal rate will be increased. However, an oxide layer is detected at contact regions to EDX. Figure 13(b) shows the EDX pattern of the worn surface of Al-1.5Mg-1.5Sn-6Es composite. Presence of iron and chromium is evidence on the worn asperities transferred from steel disk to the sample surface. A similar result is obtained by Zhang et al. [58].

In the case of 9 wt. \% of Es (Figure 14), sever crack propagation can be seen. Also, we can observe that the adhesive wear and smooth grooves return. There is a high volume of clusters that accompanied with porosities. These porosities form weak points surrounded the Es particles in the composite thus the porosities around the clusters fa- cilitate Es removing. Removing of Es particles means the absence of Es protrusions during wear process. This facilitates reaching of steel disk asperities to the matrix forming again adhesion and abrasion wear in some regions. In addition to that, deep cracks of weak regions, Es particle, slight and small grooves, a worn oxidative layer which contains debris from the sample surface and counter face disk and delaminated areas are marked in Figure 14.

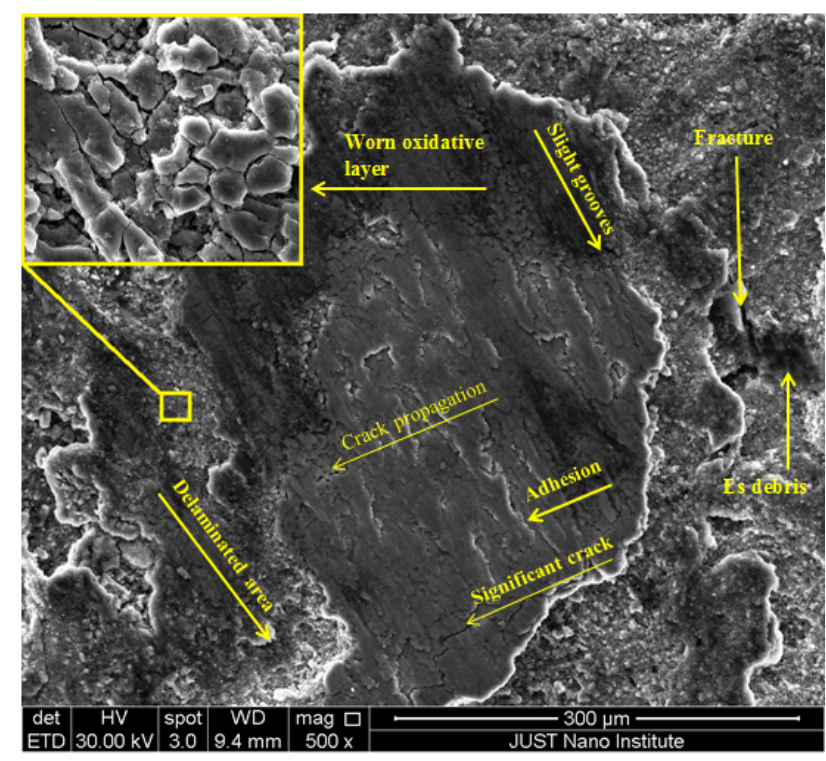

Figure 14: SEM micrograph of worn out surfaces of Al-1.5Mg-1.5Sn9Es composite showing slight grooves, delaminated area, sever crack propagation and worn oxidative layer discovered by EDX.

\subsection{X-ray diffraction (XRD) analysis}

The aim of adding magnesium to base sample as a sintering assistant has been achieved by reducing the amount of aluminum oxide $\left(\mathrm{Al}_{2} \mathrm{O}_{3}\right)$, where the $\mathrm{Mg}$ reacts with $\mathrm{Al}_{2} \mathrm{O}_{3}$ to form $\mathrm{MgO}$ according to the equation 3. This is proved in the XRD pattern as shown in Figure 15(a).

$$
3 \mathrm{Mg}+\mathrm{Al}_{2} \mathrm{O}_{3} \longrightarrow 3 \mathrm{MgO}+2 \mathrm{Al}
$$

In the sample containing 6 Es wt. \%, it can be observed the presence of calcium magnesium carbonate due to the addition of Es. Moreover, no clear peaks of $\mathrm{Al}_{2} \mathrm{O}_{3}$ are observed. It may refer to the increase of $\mathrm{Mg}$ amount included in Es, where increasing $\mathrm{Mg}$ amount leads to a lower amount of $\mathrm{Al}_{2} \mathrm{O}_{3}$ as mentioned in [59]. XRD pattern in Figure 15(b) proved the absence of aluminum oxide. 


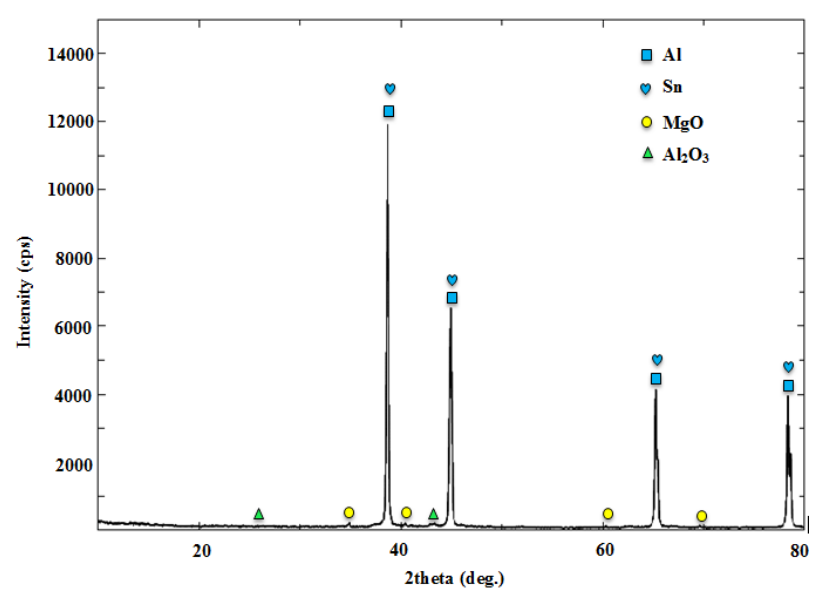

(a)

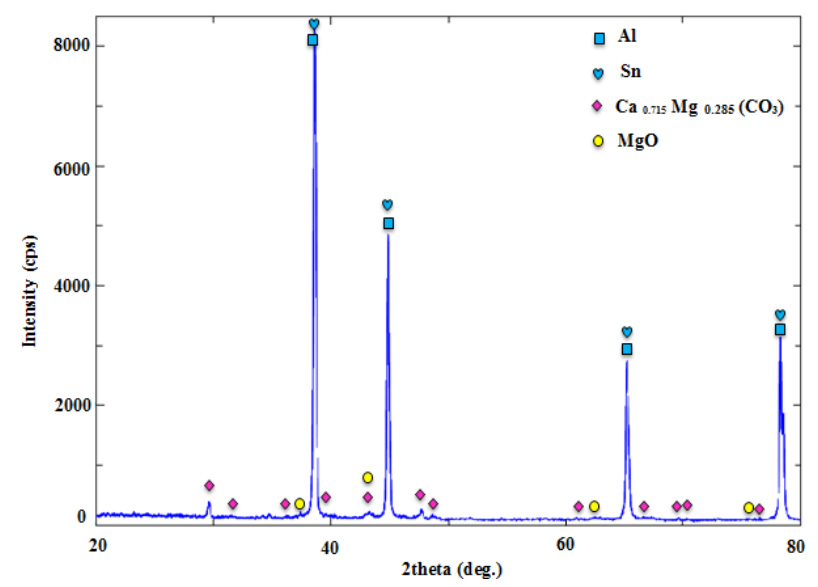

(b)

Figure 15: (a) XRD pattern of the base sample, Al-1.5Mg-1.5Sn, (b) XRD pattern of Al-1.5Mg-1.5Sn-6Es composite.

\section{Conclusion}

This study aims to investigate of the effect of eggshells green reinforcement on the mechanical and tribological properties of powdered aluminum matrix composite. Based on the results of the study, the following points can be concluded:

1. The primary Es reinforcement has positive effects on aluminum matrix properties up to 3 wt. \%. Beyond this limit, a negative effect appeared due to the clusters which are accompanied with porosity as proved in SEM micrographs.

2. The most positive effect of $3 \mathrm{wt}$ \% of Es was on wear resistance (65\% improvement), then the compressive strength (40\% improvement) and finally hardness (15 $\%$ improvement).
3. The presence of porosity negatively affects all mechanical and tribological properties of the current aluminum matrix.

4. SEM micrographs and EDX of the current composites show four types of wear that are abrasive, adhesive, delaminated and oxidative wear.

Acknowledgements: The authors are grateful for the Deanship of Scientific Research at Jordan University of Science and Technology (JUST) for the generous fund and support with grant no. 256/2017.

\section{References}

[1] Hassan S, Aigbodion V. J. King Saud Univ. Eng. Sci. 2015, 27, 4956.

[2] Esmaily M, Mortazavi N, Svensson J, Halvarsson $M$, Wessén $M$, Johansson L, Jarfors A. Composites Part B. 2016, 94, 176-189.

[3] Pirondi A, Collini L. Int. J. Fatigue. 2009, 31, 111-121.

[4] Torralba J, da Costa C, Velasco F. J. Mater. Process. Technol. 2003, 133, 203-206.

[5] Anjali R.M, Bhandari S, Pant A, Saxena A, Seema N.K, Nikhil C, Dheeraj G, Sah P.L. International Journal of Mathematical, Engineering, Management Sciences. 2017, 2, 53-62.

[6] Megahed M, Attia M, Abdelhameed M, El-Shafei A. Acta Metall. Sinica. 2017, 30, 781-790.

[7] Ibrahim I, Mohamed F, Lavernia E. J. Mater. Sci. 1991, 26, 1137 1156.

[8] Shamim S, Singh H, Sasikumar C,Yadav D. Mater. Today:. Proc. 2017, 4, 2887-2898.

[9] Surappa M, Sadhana. 2003, 28, 319-334.

[10] Gostariani R, Ebrahimi R, Asadabad M, Paydar M. Acta Metall. Sinica . 2017, 31, 245-253.

[11] Hayajneh M, Hassan A, Alrashdan A, Mayyas A. J. Alloys Compd. 2009, 470, 584-588.

[12] Chaithanyasai A, Vakchore P, Umasankar V. Procedia Eng. 2014, 97, 961-967.

[13] Kumar V, Gupta R, Batra N. Procedia Mater. Sci. 2014, 6, 13651375.

[14] Almomani M, Hayajneh M, Draidi M. Part. Sci. Technol. 2015, 34, 317-323.

[15] Cevik E, Sun Y, Turen Y, Ahlatci H. Sci Eng Compos Mater. 2018, 25, 67-73.

[16] Hayajneh M, Hassan A, Al-Omari M. J. Mater. Eng. Perform. 2001, 10, 521-525.

[17] Demir A, Altinkok N. Compos. Sci. Technol. 2004, 64, $2067-$ 2074.

[18] Rajan T, Pillai R, Pai B, Satyanarayana K, Rohatgi P. Compos. Sci. Technol. 2007, 67, 3369-3377.

[19] Hassan A, Mayyas A, Alrashdan A, Hayajneh M. J. Mater. Sci. 2008, 43, 5368-5375.

[20] Almomani M, Tyfour W, Nemrat M. J. Alloys Compd. 2016, 679, 104-114.

[21] Ogawa F, Yamamoto S, Masuda C. Acta Metallurgica Sinica (English Letters), 2018. 
[22] Mazahery A, Ostadshabani M. J. Compos. Mater. 2011, 45, 2579 2586.

[23] Al-Oqla, F., Salit, M., Materials Selection for Natural Fiber Composites (first ed.), 2017, Woodhead Publishing.

[24] Al-Oqla, F., Sapuan, S. M. J Polym Environ. 2017, 1-7.

[25] Toro P, Quijada R, Yazdani-Pedram M, Arias J. Mater. Lett. 2007, 61, 4347-4350.

[26] Bootklad M, Kaewtatip K. Carbohydr. Polym. 2013, 97, 315-320.

[27] Hassan T, Rangari V, Jeelani S. ACS Sustainable Chem. Eng. 2014, 2, 706-717.

[28] Iyer K, Torkelson J. Compos. Sci. Technol. 2014, 102, 152-160.

[29] Boronat T, Fombuena V, Garcia-Sanoguera D, Sanchez-Nacher L, Balart R. Mater. Des. 2015, 68, 177-185.

[30] Mazahery A, Shabani M. Ceram. Int. 2012, 38, 4263-4269.

[31] Moutsatsou A, Itskos G, Vounatsos P, Koukouzas N, Vasilatos C. Mater. Sci. Eng., A 2010, 527, 4788-4795.

[32] El-Kady O, Fathy A. Mater. Des. 2014, 54, 348-353.

[33] Liu J, Khan U, Coleman J. Fernandez B., Rodriguez P., Naher S., Brabazon D., Mater. Des. 2016, 94, 87-94.

[34] Tan A, Teng J, Zeng X, Fu D, Zhang H. Powder Metall. 2017, 60, 66-72.

[35] Dwivedi S, Sharma S, Mishra R. International Journal of Precision Engineering and Manufacturing-Green Technology 2016, 3, 281-288.

[36] Sharma S, Dwivedi S. Hazard J. Mater. 2017, 333, 1-9.

[37] Razavi Hesabi Z, Hafizpour H, Simchi A. Mater. Sci. Eng., A 2007, 454, 89-98.

[38] Xie G, Ohashi O, Sato T, Yamaguchi N, Song M, Mitsuishi K, Furuya K. Mater. Trans., JIM 2004, 45, 904-909.

[39] MacAskill I, Hexemer R, Donaldson I, Bishop D. J. Mater. Process. Technol. 2010, 210, 2252-2260.

[40] Jamal N, Yusof F, Nor Y, Othman M, Khalid K, Zakaria M. IOP Conference Series: Materials Science and Engineering 2018, 290, 012008.
[41] Ghiță C, Popescu I. Comput. Mater. Sci. 2012, 64, 136-140.

[42] Lin D, Yi S, Heo J, Lee J, German R, Park S. Ceram. Int. 2015, 41, 5057-5065.

[43] Heckel R.W. Trans Metall Soc AIME 1961, 221, 671-675.

[44] Vogiatzis C, Skolianos S. Composites Part A 2016, 82, 8-19.

[45] Kok M. J. Mater. Process. Technol. 2005, 161, 381-387.

[46] Sinha A, Farhat Z. Materials Sciences and Applications 2015, 6, 549-566.

[47] ASTM G99, 1997, Standard test method for wear testing with a pin-on-disk apparatus, annual book of ASTM standards, 03.02.

[48] Mahdavi S, Akhlaghi F. Tribol. Lett. 2011, 44, 1-12.

[49] Nemati N, Khosroshahi R, Emamy M, Zolriasatein A. Mater. Des. 2011, 32, 3718-3729.

[50] Ahmadi A, Toroghinejad M, Najafizadeh A. Mater. Des. 2014, 53, 13-19.

[51] Moazami-Goudarzi M, Akhlaghi F. Tribol. Int. 2016, 102, 28-37.

[52] Ravindran P, Manisekar K, Rathika P, Narayanasamy P. Mater. Des. 2013, 45, 561-570.

[53] Abdizadeh H, Ebrahimifard R, Baghchesara M. Composites Part B 2014, 56, 217-221.

[54] Gopal P, Soorya Prakash K, Nagaraja S, Kishore Aravinth N. Tribol. Int. 2017, 116, 338-350.

[55] Thandalam S, Ramanathan S, Sundarrajan S. J. Mater. Res. Technol. 2015, 4, 333-347.

[56] Sahin S, Yüksel N, Hülya D, Ýrýzalp S. Materiali in Tehnologije 2013, 4, 639-646.

[57] Wei T, Shamsuri S, Yee C., Rashid M, Ahsan Q. Procedia Eng. 2013, 68, 703-709.

[58] Zhang K, Wang Z, Wang D, Guo Y, Zhao B. Tribol. Int. 2015, 90 , 84-95.

[59] Pech-Canul M, Katz R, Makhlouf M. Metall. Mater. Trans. A 2000, $31(2), 565-573$. 